\title{
Exclusive Breastfeeding Among Mothers of Children Aged 0-6 Months: Maternal Knowledge, Attitudes, and Practices in Ethiopia
}

Nahom Eyasu ( $\square$ tenseye@gmail.com )

University of Gondar College of Social Sciences and Humanities https://orcid.org/0000-0002-90674521

Hassan Hosseinzadeh

University of Wollongong Faculty of Health and Behavioural Sciences: University of Wollongong

\section{Endrias Tesfa}

University of Gondar College of Social Sciences and Humanities

\section{Research}

Keywords: exclusive breastfeeding, knowledge, attitude, practice

Posted Date: August 9th, 2021

DOI: https://doi.org/10.21203/rs.3.rs-779095/v1

License: (a) (1) This work is licensed under a Creative Commons Attribution 4.0 International License.

Read Full License 


\section{Abstract}

Background: Globally, less than $40 \%$ of infants under six months of age are exclusively breastfed. Researchers have established the prevalence, nature, and the degree of this problem; however, less is known about the knowledge, attitudes, and practices (KAP) of exclusive breastfeeding (EBF) among mothers of children aged 0-6 months in Ethiopia. This research addresses this knowledge gap by examining (a) the maternal KAP of breastfeeding and (b) the association between sociodemographic variables and KAP.

Methods: This research draws on a sample of women $(n=415)$ from Finote-Selam town, derived using simple, systematic, and multistage sampling techniques. Data were analyzed using univariate analysis and binary logistic regression.

Results: Results show that the vulnerable groups, such as mothers being illiterate, low-income group, and lived in rural areas have encountered a double burden of death during delivery and having no knowledge of, positive attitudes, and practices of breastfeeding compared with other mothers of children aged 0-6 months because the respondents have differences in socio-economic characteristics and how they are under cultural influence. Furthermore, the results also affirmed that the age limit could also determine approaches and perceptions of mothers for the exclusive breastfeeding of mothers: mothers aged 25-34 and above 35 years old had good knowledge of and attitude towards breastfeeding, respectively. Furthermore, the poor practice of breastfeeding did not save any baseline variable, such as educational level, level of employment, and level of income.

Conclusion: This study would allow policymakers, medical sociologists, and health extension practitioners to develop more effective all-rounded interventions to minimize the poor practice of EBF.

\section{Introduction}

Exclusive breastfeeding (EBF) is defined as an infant's consumption of human milk with no supplementation of any type of food and drinks except for vitamins, minerals, and medications until six months [26]. Globally, less than $40 \%$ of infants under six months of age are exclusively breastfed, despite the documented benefits of breastfeeding [27]. However, this reduces to $38 \%$ in the developing world including Africa [27]. Suboptimum breastfeeding, particularly nonexclusive breastfeeding, results in 1.4 million child deaths and $10 \%$ of disease burden in children under five years (24). Global risk assessment of suboptimal breastfeeding indicates that $96 \%$ of all infant deaths in developing countries are attributable to inappropriate feeding occurring during the first six months of life [16].

Similarly, exclusive breastfeeding prevalence in Ethiopia is very low [3]. A study shows that this country found the prevalence of exclusive breastfeeding less than six months was 29.3\% [21]. However, only $43.6 \%$ of mothers practiced exclusive breastfeeding for the first six months after delivery [8]. This problem could result in 1 in every 17 children die before the first birthday and 1 in every 11 children dies before the fifth birthday [8]. Over 2/3 of these deaths are often associated with inappropriate feeding 
practices and occurs the first year of life in this country [28]. Today in Ethiopia, poor exclusive breastfeeding practice among mothers with an infant aged 0-6 months and a paucity of research devoted to investigate KAP of mothers towards exclusive breastfeeding is the public health and sociology of health concern [23]. Therefore, the current study aims to fill the above gaps by examining the KAP of mothers of children aged 0-6 months towards exclusive breastfeeding and associating the respondents' sociodemographic variables with maternal KAP.

\section{Method}

The community-based cross-sectional study was carried to select respondents from September to June 2019 in Finote-Selam district, which is found in Northwest Ethiopia, to assess the maternal knowledge, attitude, and practices (KAP) of exclusive breastfeeding among mothers of children aged 0-6 months in Ethiopia. This method was so important to afford numeric descriptions of knowledge, attitudes, and practices of mothers who have children in the age between 0 and $6[30,31]$.

The target population of the current study included the mothers of children aged 0-6 months but lived in Finote-Selma district of Amhara National Regional State, Ethiopia. A multi-stage random sampling technique was used to identify the actual respondents by firstly selecting mothers of children aged 0-6 months in Ethiopia. Then, within these groups, a random sample of smaller sub-groups such as mothers of children who lived in Finote-Selam and four local administrations-kebeles (2 urban kebeles: 03 \& 04 and 2 rural kebeles: Shenbekuma \& Bakel) were selected. Afterward, a sample of these smallest subgroups can be randomly selected to form a target population for the current study. After assessing the potential respondents and the study areas of the present study, the researchers undertook a systematic random sampling technique in the condition that $n$th aged 0-6 months of mothers at Finote-Selam district was selected. The simple random sampling technique was used to obtain the required sample size calculated by

$n=(Z a / 2)^{2} p(1-p)$, whereby, $d^{2}$

the prevalence of exclusive breastfeeding in Ethiopia at the national level $(P)$ was considered as $58 \%$, at a $95 \%$ confidence level, and $5 \%$ degree of desired precision (d). From this assumption, the sample was 375 . But, the total sample size for the study area was 413 by considering $10 \%$ of the non-response rate.

After selecting the actual respondents of the current study, the researchers used a paper and pencil questionnaire. The current study adopted some questions from the Ethiopia Demographic Health Survey (2016) and modified it to meet the basic objectives and considered the contextual understanding of the study area. The modified questions have checked the consistency of the questionnaire by conducting a pre-test in Burie town (a town that has a similar case of the study area), which was not included in the actual data analysis. After testing the sample questionnaire, corrections were made on unclear questions for the interviewers and interviewees. This reliability of the data was validated by Cronbach's alpha $=0.81$ indicated the quality of data was good. 
The researcher-administered questionnaire contained a total of 33 questions and was divided into four parts that addressed the participants' sociodemographic characteristics (12 questions), breastfeeding knowledge (8 questions), attitudes (5 questions), and practices (8 questions). The knowledge questions have the response options using dichotomous variables: $0=$ no, $1=$ yes whereas the items represented by five points to reflect the frequencies of maternal attitude on breastfeeding which includes (strongly disagree $=0$, disagree $=1$, neutral $=3$, agree $=4$, and strongly disagree $=5$ ), and the questions of maternal practices offered the response options using multiple choices that asked in different manners.

The participants' scoring system was as follows:

- Knowledge: Good (4-7 points), Fair (2-6 points), Poor (0-2 points);

- Attitude: Good (14-25 points), Fair (5-13 points), Poor (0-4 points); and

- Practice: Good (4-6 points), Fair (2-3 points), Poor (0-1 point).

Questions envisioned to assess the breastfeeding knowledge comprised the information the mothers have, the source of information, types of food given for the infant immediately after delivery, duration of $E B F$, importance of EBF to maternal and child health, and colostrum feeding for the infant. Questions intended to consider the breastfeeding attitude included importance of EBF for the infant's health promotion, mother's health improvement, EBF that continued for $(0-6)$ months, cheese swallow, and colostrum feeding that be necessary for the infants. Whereby, questions anticipated to examine breastfeeding practices held up a time that starting breastfeeding, frequency of breastfeeding per day, duration of breastfeeding, colostrum feeding for the infant, the types of food that infant can take in addition to BF under 6 months and the like.

The current study obtained informed consent from respondents after the purpose and procedure of the study were explained. The current study assured participants they would be protected from physical and psychological harm whilst being participants.

\section{Data analysis}

Quantitative data were analyzed starting from checking up the accuracy of the transcription of data and the translation of them from Amharic (local language) to English to checking the accuracy of the labels, the values, and level of measurement for all variables. After finishing this process as intended, the researchers conducted univariate analysis using the Statistical Package for Social Sciences (SPSS) version 20 to identify the respondents' socio-demographic variables such as age, religion, ethnicity, marital status, place of residence, education, employment status, household monthly income, and distance between house and the health center, and to analyze mean, median, standard deviation of the quantitative data.

Binary logistic regression was used to test the association between the dependent variable of exclusive breastfeeding (mothers of children aged 0-6 months carried out breastfeeding was poor Coded as 1 while not is coded as 0 ) and sociodemographic variables. Again, binary logistic regression was used to 
analyze breastfeeding KAP of mothers of children in the age between 0 and 6 months ( 1 was coded as good and 0 as not good). Breastfeeding KAP and the sociodemographic variables were entered into the regression model and then were checked for $\exp (\mathrm{B})$ to ascertain $95 \%$ of the confidence intervals $(\mathrm{Cls})$ for the odds ratio of predictor's contribution to the equation. The goodness of fit of the model was checked by Hosmer and Lemeshow test model using backward likelihood ratio method.

\section{Results}

\section{Socio-demographic background}

As outlined in Table 1, more than half of respondents were in the age group of 25-34 (55.4\%), Orthodox Christian (92\%), married (91.3\%), unemployed (69.2\%), illiterate (45.3\%) and low family income (48.4\%). However, only $61.2 \%$ of the participants were visited by health extension workers. 
Socio-demographic Characteristics' of Participants $(N=415)$

\begin{tabular}{|c|c|c|}
\hline Variables & & Frequency (\%) \\
\hline \multirow[t]{3}{*}{ Age of mother( in years) } & $15-24$ & $108(26)$ \\
\hline & $25-34$ & $230(55.4)$ \\
\hline & 35 and above & $77(18.6)$ \\
\hline \multirow[t]{2}{*}{ Religion } & Orthodox & $382(92)$ \\
\hline & Muslim/other & $33(8)$ \\
\hline \multirow[t]{2}{*}{ Marital status } & Married & $379(91.3)$ \\
\hline & Separated/ Single & $36(8.7)$ \\
\hline \multirow[t]{2}{*}{ Place of residence } & Urban kebeles & $178(42.9)$ \\
\hline & Rural kebeles & $237(51.7)$ \\
\hline \multirow[t]{3}{*}{ Level of education } & Illiterate & $188(45.3)$ \\
\hline & Primary $(1-8)$ & $121(29.2)$ \\
\hline & Secondary and above & $106(25.5)$ \\
\hline \multirow[t]{2}{*}{ Level of employment } & No employed & $287(69.2)$ \\
\hline & Employed & $128(30.8)$ \\
\hline \multirow[t]{3}{*}{ Household monthly income } & Low (0-1000) ETB & $201(48.4)$ \\
\hline & Average (1001-3000) ETB & $127(30.6)$ \\
\hline & High Above 3000 ETB & $87(21)$ \\
\hline \multirow[t]{2}{*}{ Distance between house and the health center } & No & $161(38.8)$ \\
\hline & Yes & $254(61.2)$ \\
\hline \multicolumn{3}{|l|}{ Sample Survey, 2019} \\
\hline
\end{tabular}

As presented in Table 2, the unadjusted and adjusted odds ratios described the association between the outcome variable of maternal knowledge of EBF and all the categories of the explanatory variables. The results show that the mothers who were between 25 and 34 years $(A O R=1.2,95 \% \mathrm{Cl}=[0.6-2.4])$, but lived in urban areas with having employment categorized under a high-income group $(\mathrm{AOR}=2.2,95 \% \mathrm{Cl}=$ $[1.3,4.1] ; \mathrm{UOR}=3.6,95 \% \mathrm{Cl}=[2.2,5.8])$, have higher levels of education $(\mathrm{AOR}=8.1,95 \% \mathrm{Cl}=[2.5,26.3], \mathrm{p}$ 
$<=0.025)$, and delivered their children in hospitals (UOR $=4.3,95 \% \mathrm{Cl}=[2.6,7.2])$ have had a better knowledge of breastfeeding compared to other baseline variables in more probability. 
Table 2

Logistic Regression Analysis of Maternal Knowledge of EBF-Unadjusted and Adjusted Odds Ratios with Each Demographic Variable.

Variables

Mothers' age

$\begin{array}{lll}15-24 & 1 & 1 \\ 25-34 & 1.0(0.5-1.7) & 1.2(0.6-2.4) \\ >\text { or }=35 & 0.5(0.2-0.9)^{\star \star} & 1.0(0.4-2.2)\end{array}$

Place of Residence

Urban

$2.0(1.2-3.2)^{\star \star}$

1

Rural

Educational level of mothers

Cannot read and write 1

Primary $(1-8)$

$2.1(1.2-3.5)^{\star \star}$

Secondary and above

$14.5(5.1-41.0) \star$

Employment status of the mother

No employed

1

Employee

$1.5(0.9-2.5)$

Monthly income

Low (below US\$150)

High (above US\$150)

Place of delivery

Hospital

Home

history of ANC

No visit of ANC

At least one visit

History of PNC
1

1

$1.8(0.9-3.4)$

$8.1(2.5-26.3)^{\star \star}$

$.9(0.5-1.7)$

$.8(0.9-3.4)$
$8(2.5-26.3)^{\star \star}$

\section{Unadjusted Odds Ratio [95\% Cl] Adjusted Odds Ratio [95\% Cl]}

1 


\begin{tabular}{|c|c|c|}
\hline Variables & Unadjusted Odds Ratio [95\% Cl] & Adjusted Odds Ratio [95\% Cl] \\
\hline No visit of ANC & 1 & 1 \\
\hline At least one visit & $5.2(3.2-8.3)^{\star \star \star}$ & $3.4(1.8-6.5)^{\star \star \star}$ \\
\hline \multicolumn{3}{|c|}{ *Significant at $<=0.001, * \star$ significant at $<=0.025, * \star \star$ significant at $<0.05 ; 95 \% \mathrm{Cl}$} \\
\hline \multicolumn{3}{|c|}{ Only multivariate logistic regression was used for interpretation } \\
\hline
\end{tabular}

As depicted in Table 3, the association between the outcome variable of the maternal attitude of EBF and all the categories of the explanatory variables were described by the unadjusted and adjusted odds ratios. The result reveals that the above 35 aged mothers $(\mathrm{UOR}=0.6,95 \% \mathrm{Cl}=[0.2,1.3])$ but lived in the urban area $(A O R=0.8,95 \% \mathrm{Cl}=[0.4,1.8] ; \mathrm{UOR}=2.1,(95 \% \mathrm{Cl}=[1.1,3.7], \mathrm{p}<0.05)$, completed secondary education $(A O R=8.7,95 \% \mathrm{Cl}=[2.6,28.9], \mathrm{p}<0.001)$, and visited health centers to get antenatal and postnatal care service utilization had a positive attitude towards the importance of breastfeeding compared to other socio-demographic variables. 
Table 3

Logistic Regression Analysis of Maternal Attitude of EBF-Unadjusted and Adjusted Odds Ratios with Each Demographic Variable.

\section{Variables}

Mothers age

$\begin{array}{ll}15-24 & 1 \\ 25-34 & 0.9(0.4-1.8) \\ >\text { or }=35 & 0.6(0.2-1.3)\end{array}$

Place of Residence

Urban

Rural

Educational level of mothers

Cannot read and write

Primary $(1-8)$

Secondary and above

Employment status of the mother

Not employed

1

Employed

$1.7(0.9-3.4)$

Monthly income

Low (below US\$150)

High (above US\$150)

Place of delivery

Hospital

Home

Visit of ANC

No visit of ANC

At least one visit

Visit of PNC

No visit of ANC 1
Adjusted Odds Ratio [95\% Cl] 
Variables

At least one visit

*Significant at $<=0.001, * \star$ significant at $<=0.025, * \star \star$ significant at $<0.05$
Unadjusted Odds Ratio [95\% Cl] Adjusted Odds Ratio [95\% Cl]

$4.8(2.7-8.7)^{\star} \quad 2.1(1.1-4.6)^{\star \star \star}$


Table 4

Logistic Regression Analysis of Maternal Practice of EBF-Unadjusted and Adjusted Odds Ratios with Each Demographic Variable.

$\begin{array}{cc}\text { Variables } & \text { Unadjusted Odd } \\ \text { Mothers age } & \\ 15-24 & 1 \\ 25-34 & 1.4(0.8-2.2) \\ >\text { or }=35 & 0.7(0.4-1.3)\end{array}$

Place of Residence

Urban

Rural

Educational level of mothers

Cannot read and write

Primary $(1-8)$

Secondary and above

Employment status of the mother

No employed

Employed

Low (below US\$150)

High (above US\$150)

Place of delivery

Hospital

Home

History of ANC

No visit of ANC

At least one visit

History of PNC

No visit of PNC

At least one visit $2.9(1.9-4.6)^{\star}$

1

1

1.1(0.7-1.7)

$2.5(1.4-4.4)^{\star}$

1

$1.2(0.8-1.9)$

1

$2.1(1.4-3.2)^{\star}$

$2.6(1.6-4.3)$

1
Adjusted Odds Ratio [95\% Cl] 


\section{Association between Socio-demographic Variable and Maternal Practice}

Table 7 reveals the comparison of maternal practices of EBF across socio-demographics. Binary logistic regression's result indicated that the poor practice of breastfeeding in the study area did not save any baseline variable, such as educational level, level of employment, and level of income. However, ages, place of residence, and place of delivery of mothers of children aged between 0 and 6 months have less likely affected to the poor practice of EBF.

\section{Discussions}

Despite the fact that a plethora of literature tried to describe the factors that affecting EBF in different countries $[1,18,20]$, a wide range of studies could not pay due attention to maternal knowledge, attitudes, and practices of EBF in Ethiopia. The major contribution of the current study lies in its attempt to show the KAP of mothers of children aged $0-6$ ages and their association with sociodemographics.

Binary logistic regression analysis showed that mothers who attended secondary school and above were 8 times more likely to have good knowledge about EBF compared to those who were illiterate. This finding is similar to the studies that were carried out in Ethiopia. The studies found out that maternal education has a significant role in improving knowledge about EBF practice in the first 6 months of child age $[5,9,11,13]$. Household monthly income was also another possible determinant factor significantly associated with maternal knowledge about EBF. The current study found out that the upper-income group is seen at greater importance to have a good knowledge of EBF. The previous studies have also assured this finding $[4,10]$. The present study also found out that mothers who visited antenatal and postnatal care had higher probabilities of acquiring knowledge of breastfeeding compared to mothers who delivered at home. Congruently, other studies also confirmed the present finding is that maternal history of ANC and PNC service utilization was significantly associated with better maternal knowledge on EBF than those who had no attend ANC and PNC services $[7,26]$.

In the case of the maternal attitude of EBF, the current research affirmed that the mothers who were 35 ages and above attended in the secondary education and frequently visited health centers to utilize antenatal and postnatal care service had a positive attitude towards the importance of breastfeeding compared to other socio-demographic variables. Similarly, a wide range of studies assured the current finding. For example, the studies depicted that the aged mother [23] who lived in an urban area [22] and completed secondary education [7] but visited health centers [2, 7] have had higher tendencies to have appositive attitude towards breastfeeding.

In relation to the maternal practices of EBF, the present study found out that the poor practice of breastfeeding in the study area did not save any baseline variable. This finding has not been supported by the previous studies. For example, a broader range of studies $[14,17,29]$ revealed that maternal attitudes towards early breastfeeding has a direct effect on maternal practices and yet negative attitudes 
of mothers towards breastfeeding may adversely affect practice regardless of age, education, religion, marital status, and so forth.

\section{Conclusion And Recommendation}

The current study examined maternal knowledge, attitudes, and practices of exclusive breastfeeding among mothers of children aged 0-6 months in Ethiopia. The results showed that despite the fact that mothers who lived in urban areas have a better knowledge of and attitude towards EBF compared to mothers who lived in a rural area, the practice of EBF have not observed a significant change in mothers who lived in both places of residence. This means having good knowledge of and positive attitudes toward EBF are not guaranteed to mothers of children aged between 0 and 6 months to practice EBF in more probable because the respondents have similarities in socio-economic characteristics and how they are under the cultural influence. This study has remarkably concluded that if the percentage of knowledge of and attitude towards EBF remained growing, the level of the practice of EBF became declining as the poor practice of EBF did not save any baseline variable. Therefore, the findings require further research to examine factors that affect good knowledge and positive attitudes of mothers towards breastfeeding may adversely affect the practice of EBF. Such studies would allow policymakers, medical sociologists, and health extension practitioners to develop more effective all-rounded interventions to minimize the poor practice of EBF.

\section{References}

1. Bomstein, M., \& Hendricks, C. (2012). Screening for developmental Disabilities in developing Countries. PMC.

2. Agampodi, B., Agampodi, C., Piyaseeli, D. (2007). Breastfeeding practices in a public health field practice area in Sri Lanka: a survival analysis. Int Breastfeed J, 2:13.

3. Ahmed, A. (2008). Breastfeeding preterm infants: an educational program to support mothers of preterm infants in Cairo, Egypt. Pediatric Nursing, 34(2), 125-130, 138.

4. Ali, M. (2012). Exclusive breastfeeding: mothers' awareness and health care providers practice during antenatal visits in Mvomero, Tanzania.

5. Armstrong, J., \& Reilly, J. (2002). Breastfeeding and lowering the risk of childhood obesity, Lancet359 (9322): 2003-4.

6. Belayneh, K., Zenebu, B., Alayou, G., Ahimed A., Bereket, C., Abreham, A., Amanuel, Y., \& Keno, T. (2015). Knowledge and practice of mothers towards exclusive breastfeeding and its associated factors in Ambo woreda west Shoa zone Oromia region, Ethiopia.

7. Berihun, A, \& Berhanu, B. (2014). Breastfeeding practice and associated factors among female nurses and midwives at North Gondar Zone, Northwest Ethiopia: a cross sectional institution based study. International Breastfeeding Journal 9: 11.Boateng \& Mavis F (2018). Knowledge, attitude and practice of exclusive breastfeeding among mothers in Techiman, Ghana. 
8. CARE (2010). Infant and Young Child Feeding Practices. Collecting and Using Data: A Step-by-Step Guide: Cooperative for Assistance and Relief Everywhere, Inc

9. CAR-USA (2010). Infant and young child feeding practices. Collecting and using data: A step-by-step guide 2010.

10. Central Statistical Agency of Ethiopia and ICF International (2012). Ethiopia demographic and health survey, 2011. Addis Ababa, Ethiopia and Calverton, Maryland, USA. UNICEF. Nutrition-breastfeeding.

11. Central Statistical Agency (2016). Ethiopia Demographic and Health Survey 2016.

12. Dennis, C. (2002). Breast feeding initiation and duration: a 1990-2000 literature review, Journal of Obstetrics and Gynecology, 31(1): 12-32.

13. Dennison, A., Hawke, A., Ruberto, A., \& Gregg, J. (2015). Implementing legislation to improve hospital support of breastfeeding, New York State, 2009-2013.

14. Dessalegn, T., \& Shikur, M. (2013). Maternal Knowledge of Optimal Breastfeeding Practices and Associated Factors in Rural Communities of Arba Minch Zuria, International Journal of Nutrition and Food Sciences, 2(3): 122-129.

15. Dieterich, M., Felice, P., O'Sullivan, E., \& Rasmussenm, M. (2013). Breastfeeding and health outcomes for the mother-infant dyad. Pediatric clinics of North America,.60 (1):31-48.

16. Ekambaram, M., Bhat, B., Asif, M., \& Ahmed, P. (2010). Knowledge, attitude and practice of breastfeeding among postnatal mothers, Curr Pediatr Res, 14 (2): 119-124.

17. El-Gilany, H., Shady, E., \& Helal, R. (2011). Exclusive breastfeeding in Al-Hassa, Saudi Arabia. Breastfeed Med, 6(4): 209e213.

18. El-Gilany, H., Shady, E., \& Helal, R. (2010). Exclusive breastfeeding in Al-Hassa, Saudi Arabia. Breastfeed Med. 2011;6 (4):209-13. 32. Federal Democratic Republic of Ethiopia Ministry of Health. Health Sector Development Programme IV 2010/11-2014/15. October, 2010.

19. Federal Ministry of Health. (2004). National strategy for infant and young child feeding. Addis Ababa, Ethiopia.

20. Fewtrell, M., Wilson, C., Booth, I., \& Lucas, A. (2011). Six months of exclusive breastfeeding: how good is the evidence?

21. Fincham, E. (2008). Response rates and responsiveness for surveys, standards, and the Journal. American Journal of Pharmaceutical Education, 72(2), 43.

22. Fosu- Brefo, R., \& Arthur, E. (2015). Effect of timely intervention of breastfeeding on child health in Ghana. Health Economic Review, 5:8.

23. Garg, R., Deepti, S., Padda, A., \& Singh, T. (2010). Breastfeeding knowledge and practices among rural women of Punjab, India: a community-based study. Breastfeeding Medicine: The Official Journal of the Academy of Breastfeeding Medicine, 5(6), 303-307.

24. Getnet, M., \& Melkie, E (2015). Exclusive breastfeeding and associated factors among mothers in Debre Markos, Northwest Ethiopia: a cross-sectional study 
25. Guendelman, S., Kosa, K., Peal, M., Graham, S., Goodman, J., \& Kharrazi M. (2009). Juggling work and breastfeeding: Effects of maternity leave and occupational characteristics. Pediatrics, 123-e38e46.

26. Heymann, A., \& Raub., E. (2013). Breastfeeding policy: a globally comparative analysis," Bulletin of the World Health Organization, 91(6): 398-406.

27. Imdad, M., Yakoob, Z., \& Bhutta, A. (2011). Effect of breastfeeding promotion interventions on breastfeeding rates, with special focus on developing countries, BMC Public Health, vol. 11(3).

28. Khamnian, A., Azarfar, Z., Ravanshad, Y., \&Hashemian, M. (2013). Exclusive breastfeeding and factors affecting knowledge, attitude and practice of mothers in rural and urban regions of East Azerbaijan, Iran. Life Science Journal, 10(5s):473-478.

29. Kibebew, A. (2012). Infant and young child feeding practice among mothers living in Harer, Ethiopia. Harar Bulletin of Health Sciences. January 2012; 4.

30. Kitano, N., Nomura, K., Kido, M., Murakami, K., Ohkubo, T., Ueno, M., \& Sugimoto, M. (2016). Combined effects of maternal age and parity on successful initiation of exclusive breastfeeding. Preventive Medicine Reports, 3, 121-126.

31. Kok, Tan (2004). Factors associated with exclusive breastfeeding among infants under six months of age in peninsular Malaysia" International Breastfeeding Journal 2011, 6:2La Leche League International (2004). The womanly Art of Breastfeeding. 7th ed. Schaumburg.

32. Labbok, M., \& Taylor, E. (2008). Achieving exclusive breastfeeding in the United States: findings and recommendations, Washington, DC: United States Breastfeeding Committee.

33. Lamberti, M., Fischer, Walker, C., Noiman, A., Victora, C., Black, E. (2011). Breastfeeding and the risk for diarrhea morbidity and mortality. BMC Public Health. 2011; 11.

34. Loss, E., Wainaina, F., Bailey, C. (2004). Prevalence and predictors of underweight, stunting, and wasting among children aged 5 and under in western Kenya.

35. Maeza, M., Mesele, A., Zelalem, K. (2015) Factors associated with exclusive breastfeeding practices in Debre Berhan District, Central Ethiopia: a cross sectional community based study. International Breastfeeding Journal, 10:23.

36. Mangrio, E., Persson, K., \& Bramhagen, C. (2017). Socio demographic, physical, mental and social factors in the cessation of breastfeeding before 6 months: a systematic review. Scandinavian Journal of caring sciences; 10: 1471-6712.

37. Mavis, F. (2018). Knowledge, Attitude and Practice of exclusive Breastfeeding among mothers in techiman, Ghana. University of Eastern Finland.

38. Mensah, A., Acheampong, E., Anokye, F., Okyere, P., Appiah-Brempong, E., \& Adjei, O. (2017). Factors influencing the practice of exclusive breastfeeding among nursing mothers in a periurban district of Ghana. BMC Research Notes; 10:466.

39. Mossman, M., Heaman, M., Dennis, L., \& Morris, M. (2008). The influence of adolescent mothers $\$ breastfeeding confidence and attitudes on breastfeeding initiation and duration. Journal of Human Lactation: Official Journal of International Lactation Consultant Association, 24(3), 268-277. 
40. Mucheru, P., Waudo, J., \& Chege, P. (2016). Relationship between Maternal Knowledge on Exclusive Breastfeeding and Breastfeeding Practices Among Mothers with Infants (0-6 Months) in. International Journal of Health Sciences \& Research.

41. Mulugeta, W., Netsanet, H., Nigusie, B., \& Selam, F. (2017) knowledge and attitude towards exclusive breastfeeding among mothers attending antenatal care services and immunization at Dabat health center, North West Ethiopia.

42. Tadele, N. \& Habta, F. (2015). Knowledge, attitude and practice towards exclusive breastfeeding among lactating Mothers, Mizan Aman Town, Southwestern Ethiopia: Journal of Health Education Research\& Development, 3(3), 2015.

43. National Health and Medical Research Council (2012). Infant Feeding Guidelines. Canberra: National Health and Medical Research Council.

44. Nicklas, T. (2011). The role of religion and spirituality in counseling.

45. Oche, O., Umar, S., Ahmed, H. (2011). Knowledge and practice of exclusive breastfeeding in Kware, Nigeria. AFHS1103-0518.

46. Oddy, W., Kendall, E., Li, J., Jacoby, P., Robinson, M., de Klerk, H., Silburn, R., Zubrick, R., Landau, I., \& Stanley, F. (2010). The long-term effects of breastfeeding on child and adolescent mental health: a pregnancy cohort study followed for 14 years, The Journal of Pediatrics 156 (4): 568-574.

47. Owusuaa, L. (2015). Infant feeding practices and their relation to maternal health care utilization. A national cross-sectional study among Ghanaian women.

48. Robert, B., Lindsay, H., Allen, A., Bhutta, Laura, C., Mercedes, O., Majid, E., Colin, M., \& Juan, R. (2008), Maternal and child undernutrition: global and regional exposures and health consequences. The Lancet, 371 (9608): 243-260.

49. Ryan, S., et al. (2006). The effect of employment status in the United States, Women Health Issues, 16(5): 243-251.

50. Sefene, D., Birihanu, W., Awoke, \& Taye, T. (2013). Determinants of exclusive breastfeeding practice among mothers of children age less than 6 month in Bahir Dar city administration, Northwest Ethiopia; a community based cross-sectional survey, Science Journal of Clinical Medicine, 2(6): 153159.

51. Setegn, T., Gerbaba, M., \& Belachew, T. (2012). Factors associated with exclusive breastfeeding practices among mothers in Goba district, south east Ethiopia: a cross-sectional study International Breastfeeding Journal.

52. Shommo, S., \& Al-Shubrumi, H. (2014). Breastfeeding knowledge, attitude and practice among mothers in Hail district, northwestern Saudi Arabia, 3(1), 49-56.

53. Stein, Z., \& Kuhn, L. (2009). Breast Feeding: A Time to Craft New Policies. Journal of Public Health Policy, 30 (3): 3-6.

54. Tamiru, D., Belachew, T., Loha, E., \& Mohammed, S. (2012). Sub-optimal breastfeeding of infants during the first six months and associated factors in rural communities of Jimma Arjo Woreda, Southwest Ethiopia. BMC Public Health, 12:363. 
55. Tampah-Naah, A., \& Kumi- Kyereme, A. (2013). Determinants of exclusive breastfeeding among mothers in Ghana: a cross sectional study. International Breastfeeding Journal.

56. Tan, L. (2011). Factor associated with exclusive breastfeeding among infants under six months of age in Peninsular Malaysia. International Breastfeeding Journal, 6:2.

57. Tawiah, A., Bazzano, K., \& Zelee H. (2008). Early initiation of breast feeding in Ghana journal of perinatology.

58. Tigest, S., Amare, W., \&Yemane, B. (2015). Factors associated with exclusive breastfeeding practices of urban women in Addis Ababa public health centers, Ethiopia: a cross sectional study. International Breastfeeding Journal, 10: 22.

59. Tigest, S., Amare, W., \& Yemane, B. (2015). Factors associated exclusive breastfeeding practices of urban women in Addis Ababa public health centers, Ethiopia: a cross sectional study.

60. Titilola, T., \& Obilade, M. (2015), The Knowledge, Attitude and Practice of Exclusive Breastfeeding among Mothers in Two Semi-Urban Areas around a Baby Friendly Hospital Initiative (BFHI) designated hospital in Lagos State, Nigeria.

61. Tsedeke, W., Gadisa, D., Ababa, W., Gene,t M., Girma, N., Habtamu, D., Tadesse, B., \& Eyasu. E. (2014), Knowledge, Attitude and Practice of Exclusive Breast Feeding Among Lactating Mothers in Bedelle Town, Southwestern Ethiopia: Descriptive Cross Sectional Study. Nekemte Wollega University.

62. UNICEF. (2006). Progress of children-exclusive breast Feeding: a report card on nutrition: number 4, May 2006.

63. UNICEF. (2011), "A conceptual framework and research approach for identifying, analyzing and prioritizing barriers to effective maternal, newborn and child health interventions 2011," http://innovationsformnch.org/uploads/publications/2011-01.

64. UNICEF. (2010). Breastfeeding pamphlets. UNICEF in collaboration with Ministry of Health and Child Welfare in Nigeria.

65. United Nations Children's Fund (2010). Improving Exclusive Breast Feeding Practices by using Communication for Development in Infant and young Child Feeding Programs.

66. United Nations Children's Fund (2016). Community based infant and young child feeding.

67. USAID. (2008). MCH program description, overall MCH and health sectors situation; Ethiopia, 2008.

68. Victor, M., Michael, D., \& Patience, G. (2016). Knowledge, attitudes and determinants of exclusive breastfeeding practice among Ghanaian rural lactating mothers

69. Victora, G., Bahl, R., Barros, J., França, V., Horton, S., Krasevec, J. (2016). Breastfeeding in the 21st century: epidemiology, mechanisms, and lifelong effect. Lancet, 475-90.

70. Vogel, A., Hutchison, B. L., \& Mitchell, E. A. (1999). Factors associated with the duration of breastfeeding, Acta Paediatrica, 88, 1320-1326.

71. World Health Organization. (2009). Infant and young child feeding: model chapter for textbooks for medical students and allied health professionals. 
72. World Health Organization. (2010). Indicators for assessing infant and young child feeding practice. USAID part Geneva.

73. World Health Organization. (2010). "Indicators for assessing infant and young child feeding practices, part 3. Country profiles," http://www.unicef.org/nutrition/files/IYCF Indicators part III country profiles.

74. World Health Organization. (2011), the optimal duration of exclusive breastfeeding: report of an expert consultation. Geneva: World Health Organization Department of nutrition for health and development and department of child and adolescent health and development; 2011.

75. World Health Organization. (2016). Infant and Young Child Feeding. World Health Organization 88:1-80.

76. Akinremi, Z., \& Samuel, F. (2015), Knowledge and attitude of exclusive breastfeeding among hairdresser apprentices in Ibadan, Nigeria. British Journal of Medicine and Medical Research, 5(3): 376-385.

77. Zhang, K., Tang, L., Wang, H., Qiu, Q., Binns, C., \& Lee, A. (2015). Why do mothers of young infants choose to formula feed in China? Perceptions of mothers and hospital staff. International Journal of Environmental Research and Public Health, 12(5): 4520-4532. 